We thank the staff of the Milton S Hershey Medical Center, Hershey, $\mathrm{Pa}$, who contributed much to the management of the patient, particularly Drs T McGlynn and William Graham.

1 McCarthy, D M, et al, Annals of Internal Medicine, 1978, 87, 668.

2 McCarthy, D M, Gastroenterology, 1978, 74, 453.

${ }^{3}$ McCarthy, D M, et al, in Cimetidine, Excerpta Medica International Conference Series, 1978, 443, 157.

Stage, J G, et al, in Cimetidine, Excerpta Medica International Conference Series, 1978, 443, 137.

5 Basso, N, and Passaro, E, jun, fournal of Surgical Research, 1972, 13, 32.

(Accepted 26 April 1979)

National Institute of Arthritis, Metabolism, and Digestive Disease,

National Institutes of Health, Bethesda, Maryland, USA

DENIS M MCCARTHY, MD, senior investigator, digestive diseases branch STEVEN R PEIKIN, MD, clinical associate, digestive diseases branch RICHARD N LOPATIN, MD, clinical associate, digestive diseases branch BILL W LONG, MD, clinical associate, digestive diseases branch

ALLEN SPIEGEL, MD

STEPHEN MARX, MD

Surgical Division, National Cancer Institute, Bethesda, Maryland, USA

MURRAY BRENNAN, MD, senior investigator

\section{Anterior synovial rupture of ankle joint presenting as deep venous thrombosis}

Posterior synovial rupture of the knee joint with resultant oedema and swelling in the calf closely resembles deep venous thrombosis. ${ }^{1}$ This occurs most commonly in patients with rheumatoid arthritis but occasionally in other forms of arthritis. ${ }^{2}$ We report a case of monoarthritis of the ankle joint presenting with acute swelling of the ankle and calf due to anterior synovial rupture mimicking deep venous thrombosis.

\section{Case report}

A 27-year-old woman presented to the casualty department with a three-day history of painful swelling of the left ankle and calf. Deep crura venous thrombosis was diagnosed, but closer questioning disclosed a threemonth history of intermittent painful swelling of the ankle after minor trauma. Three days before admission the ankle had become hot, painful, and swollen but she had continued to walk, though with difficulty, and the swelling and pain had spread to the whole leg below the knee. Examination confirmed swelling of the calf and ankle but with maximum tenderness around the ankle joint, which was warm. Minimal calf tenderness was noted, and there was pain in the calf on dorsiflexion of the foot (Homans's sign) No other abnormalities were found apart from mild genu recurvatum.

After a period of bed rest the calf swelling had diminished considerably and a fluctuant cystic swelling $5 \mathrm{~cm}$ in diameter could be palpated above and anterior to the ankle joint; from this $20 \mathrm{ml}$ of straw-coloured fluid was aspirated, which contained $12 \times 10^{9}$ cells $/ 1\left(12000 / \mathrm{mm}^{3}\right)$, mainly neutrophils, but no crystals. Culture was negative. Synoviography of the ankle join showed a communication between the joint and the swelling but not into the calf, with only minor leakage of contrast material (figure). We considered that the calf swelling and pain were secondary to the release of some irritan synovial fluid into the tissues of the leg consequent to joint rupture, the rest of this fluid forming the cystic swelling. No localised swelling had been previously noticed by the patient. Phlebography was not considered necessary in view of the rapid clinical improvement.

Other investigations showed haemoglobin $12 \cdot 1 \mathrm{~g} / \mathrm{dl}$; white cell count $7 \times 10^{9} / 1\left(7000 / \mathrm{mm}^{3}\right)$; plasma viscosity $1.70 \mathrm{cp}$; and urate concentration $0.31 \mathrm{mmol} / 1(5.2 \mathrm{mg} / 100 \mathrm{ml}$ ) (normal $0.09-0.36 \mathrm{mmol} / 1 ; 1.5-6.0 \mathrm{mg} / 100 \mathrm{ml}$ ). An RA latex test was negative and antinuclear antibodies absent. An $x$-ray film of the ankle showed a short segment of periosteal reaction at the medial aspect of the lower tibia; sacroiliac joints were normal. HLA antigens A1 and 32 and $B 8$ and 15 were present.

\section{Comment}

Synovial rupture in inflammatory arthritis causes the release of irritant synovial contents resulting in pain and swelling. ${ }^{1}$ When the knee joint is affected the resulting clinical picture closely resembles

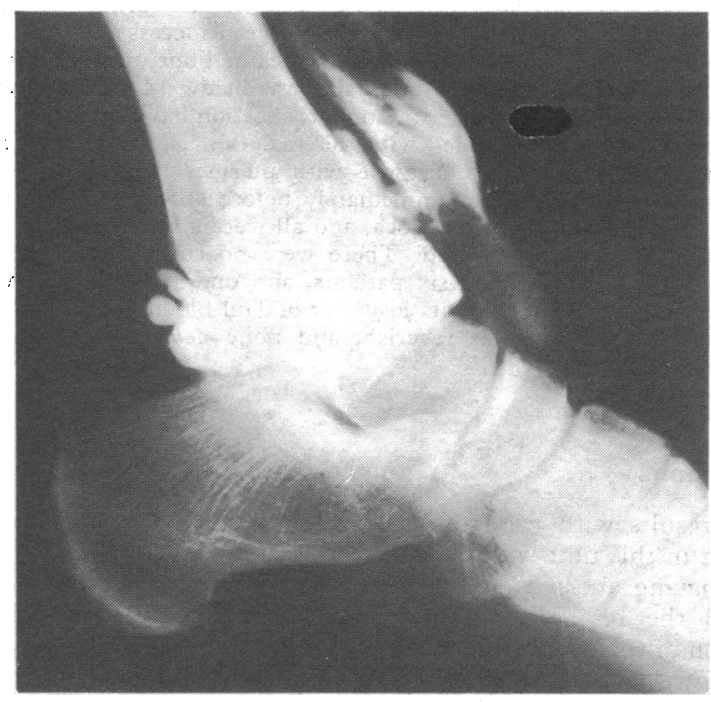

Synoviogram of left ankle joint showing immediate communication with synovial cyst.

that of deep venous thrombosis and is not uncommon in patients with early rheumatoid arthritis. ${ }^{1}$ Other joints may also rupture, including the wrist, elbow, shoulder, and hip, but rupture of the ankle joint is rare $^{3}$ Baker first reported a case of a large synovial cyst anterior to the ankle joint causing swelling in $1885 . .^{4}$ Synoviography of the ankle joint in rheumatoid arthritis has shown synovial outpouches and connections with tendon sheaths but no large anterior cysts or rupture. ${ }^{5}$

Studies of pressure in the knee joint show that enormous rises occur during normal use when an effusion is present, ${ }^{1}$ which are highest in patients with rheumatoid arthritis. High pressures might be expected in other weight-bearing joints such as the ankle, and it is surprising that rupture is so rare.

We are unaware of any report of synovial rupture of the ankle joint causing the degree of pain and swelling seen in this case and also of such rupture occurring so early in a monoarthritis. Anterior synovial rupture of the ankle joint must be considered in the differential diagnosis of deep venous thrombosis.

We wish to thank Dr A St J Dixon, consultant rheumatologist, for permission to report this case.

1 Dixon, A St J, and Grant, C, Lancet, 1964, 1, 742.

2 Bacon, P A, and Gerber, N J, Rheumatology and Rehabilitation, 1974 $13,98$.

${ }^{3}$ Gerber, N J, and Dixon, A St J, Seminars in Arthritis and Rheumatism, 1974, 3, 323.

- Baker, W M, St Bartholomew's Hospital Reports, 1885, 21, 177.

5 Hug, G, and Dixon, A St J, Annals of the Rheumatic Diseases, 1977, 36, 532 .

(Accepted 20 April 1979)

Royal National Hospital for Rheumatic Diseases, Bath BA1 1RL

D G I SCOTT, MB, MRCP, registrar in rheumatology

B J M SCHLECHT, MD, MRCP, senior house officer in rheumatology (present address: Frenchay Hospital, Bristol)

\section{Aneurysm after arterial puncture in Behçet's disease}

Behçet's disease may be complicated by aneurysms of both central ${ }^{12}$ and peripheral arteries. ${ }^{3}$ We report a case in which arterial puncture apparently predisposed to aneurysm.

\section{Case history}

A 24-year-old Saudi Arabian soldier had suffered for eight years from recurrent episodes of oral, inguinal, and scrotal ulcers; non-deforming 
arthritis with effusion in the knees, ankles, and hips; and skin eruption. The eruption consisted of acneiform lesions, lesions resembling erythema nodosum but with central ulceration, and erythema multiforme-like lesions inside both thighs. The scratch test ${ }^{1}$ was positive. An episode of iritis had occurred one year before. Haematological, biochemical, and coagulation profiles were normal apart from a diffuse polyclonal gammopathy and an erythrocyte sedimentation rate of $44 \mathrm{~mm}$ in first hour. Serological tests for rheumatoid factor, hepatitis B antigen, syphilis, and antinuclear factor and a sickle-cell preparation were negative. Several blood and urine cultures were negative.

In June 1977 the right hip was aspirated at another hospital because tuberculous arthritis was suspected. A pulsatile mass developed in the righ groin one month later and the patient was referred to this hospital. Angiography via the left femoral artery showed a saccular aneurysm of the right common femoral artery. Aneurysmorrhaphy was performed on 30 July. He was readmitted on 4 April 1978 with a pulsatile mass and bruit in the left groin at the site of angiography. An aortogram via the right brachia artery showed a $6 \mathrm{~cm}$ saccular aneurysm of the distal left common femoral artery at the site of previous puncture (see figure) and a satisfactory appearance of the right femoral artery repair. A false aneurysm occurred at

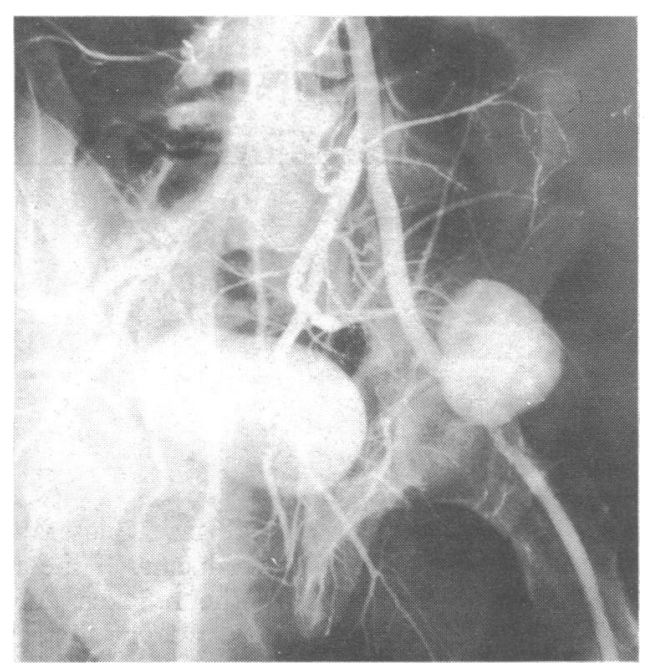

Aortogram via right brachial artery approach showing large aneurysm of left external iliac artery and satisfactory postoperative appearances of right femoral artery.

the distal anastomotic site 22 days after operation, which was treated surgically. On 1 May an aneurysm developed in the right axilla at the site used for arteriography. Simple aneurysmorrhaphy with a Dacron sleeve was performed. The aneurysm recurred 35 days later and aneurysmorrhaphy was repeated. Azathioprine $150 \mathrm{mg}$ daily was begun on 4 May. In February 1979 clinical and ultrasound examination showed an adequate circulation in both legs and no recurrence of aneurysm. Histological specimens of arterial wall taken at three of the operations showed no vasculitis or infiltration with abnormal cells.

Superficial breakdown of the wound, not affecting the graft, occurred after each operation. The appearance of the wound, absence of purulent discharge, and sterile cultures of wound and blood suggested that infection was not the cause. The two angiograms were obtained without complication by the Seldinger technique of percutaneous arterial puncture using a No 7 French-gauge catheter.

\section{Comment}

The manifestations in this patient satisfied the criteria for Behçet's disease. $^{4}$ Spontaneous aneurysms ${ }^{1-3}$ and recurrence of aneurysms after repair $^{3}$ are recognised complications. The development of aneurysms in three different arteries in the vicinity of needle insertion suggested that arterial puncture was the cause. Since aneurysms rarely occur after angiography 5 (none developed in 700 other patients who had angiography at this hospital) we think that Behçet's disease was the predisposing factor.

Aneurysm formation, poor wound healing, as in our patient, and a positive scratch-test response may be due to a similar mechanism arising from a pathological response of collagen tissue to injury. This response has important implications for patients with Behçet's disease when angiography or arterial blood sampling is required. We conclude that arterial puncture may be hazardous to patients with Behçet's disease and that wound breakdown may be a manifestation. We emphasise the tendency for the recurrence of aneurysm after repair.

Requests for reprints should be addressed to: Office of Medical Affairs, King Faisal Specialist Hospital and Research Centre, PO Box 3354, Riyadh, Kingdom of Saudi Arabia.

1 Chajek, T, and Fainaru, M, Medicine, 1976, 54, 179.

2 Hills, E A, British Medical fournal, 1967, 4, 152.

3 Jenkins, A McL, et al, British Fournal of Surgery, 1976, 63, 199.

${ }^{4}$ O'Duffy, J D, Revue de Médecine, 1974, 36, 2371.

5 Antonovic, R, Rosch, J, and Dotter, C T, American fournal of Roentgenology, 1976, 126, 386.

(Accepted 30 April 1979)

King Faisal Specialist Hospital and Research Centre, Riyadh, Saudi Arabia

MICHAEL KINGSTON, MD, FRCP, consultant internist JOHN R RATCLIFFE, MD, FACS, consultant general surgeon

MICHAEL ALLTREE, DMR(D), radiologist (now senior registrar in radiology, King's College Hospital, London SE5 9RS)

K ALVIN MERENDINO, MD, FACS, consultant thoracic surgeon
ONE HUNDRED YEARS AGO At the close of October or beginning of November, 1878, a body of Cossacks, returning from the seat of war in Turkey, reached their village, in a district of the province of Astrachan, adjoining the river Volga. Soon after their arrival, much sickness broke out among them in the form of inflammatory fever and petechial typhus. None of the men had suffered from typhus, or indeed sickness of any kind, on the journey, and it is assumed that they carried the germs of the disease with them from the infection camps in Roumelia or Bulgaria (it is not stated which province). The diseases named prevailed for a short time among the men and their families, and then began, as it was thought, to die out; when, late in December, following upon a sudden thaw, a singular and most fatal outbreak of the typhus occurred, carrying off in two days nearly a fourth of the population-that is to say, destroying 143 people out of a total population of 600 ! As soon as the terrible fatality of the disease was observed, a panic seized the people; they fled in mass, leaving the sick, the dying, and the dead alone and unattended to. The alarm was carried to neighbouring villages; the terrible word plague was uttered in self-defence, the neighbouring populations placed armed guards on all the roads leading to the infected village, and prevented any approach to it. Unhappily, the one military doctor of the district was an early victim of the disease, and some little time elapsed before by the interference of the Government of the province, measures could be taken to undeceive the people as to the nature of the malady. The rapid flight of the infected population had carried the infection into neighbouring districts; and, as the disease declared itself here and there, the local authorities, falling in with the wishes and feelings of the people, instituted measures of quarantine, in an endeavour to shut in the infected localities. These local measures were not merely approved by the Imperial Government, but that Government, apparently affected by the local panic, took immediate steps to strengthen them, and if possible to shut out the infected district of Astrachan from the rest of Russia, by sealing every thoroughfare communicating with it. At the same time that instructions were given for this being done, medical men were sent to the spot to make inquiry as to the true nature and extent of prevalence of the disease which had caused the alarm. So rapidly were these measures carried into effect, that the same telegram which informed the people of St Petersburg of the establishment of the larger measure of quarantine instituted by the Imperial Government appears to have informed them also that they were superfluous; that the disease was, in fact, typhus of the same sort as had recently existed in the capital city itself; and that it had all but died out. Nevertheless, in spite of (perhaps, in consequence of) these assurances, the alarm as to the events in Astrachan spreads in Russia, and the Imperial measures of quarantine are persisted in. (British Medical fournal, 1879.) 